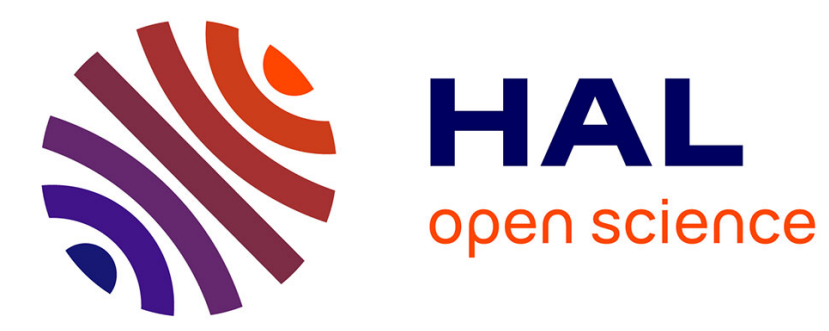

\title{
Glow discharge plasma nitriding of low alloy steel
}

K. Ram Mohan Rao, Kalimi Trinadh, C. Nouveau

\section{To cite this version:}

K. Ram Mohan Rao, Kalimi Trinadh, C. Nouveau. Glow discharge plasma nitriding of low alloy steel. Materials Today: Proceedings, 2019, 19, pp.864-866. 10.1016/j.matpr.2019.08.224 . hal-03081142

\section{HAL Id: hal-03081142 \\ https://hal.science/hal-03081142}

Submitted on 18 Dec 2020

HAL is a multi-disciplinary open access archive for the deposit and dissemination of scientific research documents, whether they are published or not. The documents may come from teaching and research institutions in France or abroad, or from public or private research centers.
L'archive ouverte pluridisciplinaire HAL, est destinée au dépôt et à la diffusion de documents scientifiques de niveau recherche, publiés ou non, émanant des établissements d'enseignement et de recherche français ou étrangers, des laboratoires publics ou privés. 


\title{
Glow discharge plasma nitriding of low alloy steel
}

\author{
K. Ram Mohan Rao ${ }^{\mathrm{a}, *}$, K. Trinadh ${ }^{\mathrm{a}}$, C. Nouveau ${ }^{\mathrm{b}}$ \\ ${ }^{a}$ Department of Chemistry, GITAM Institute of Science, Gandhi Institute of Technology \& Management, Deemed to be University Rushikonda, Visakhapatnam 530045, Andhra \\ Pradesh, India \\ ${ }^{\mathrm{b}}$ Laboratoire Bourguignon des Matériaux et Procédés (LaboMaP), Arts et Métiers Paris Tech de Cluny, Rue Porte de Paris, F-71250 Cluny, France
}

\section{A R T I C L E I N F O}

\section{Article history:}

Received 30 July 2019

Accepted 13 August 2019

Available online 25 September 2019

\section{Keywords:}

Hardness

Plasma

Diffusion

Steel

X-ray diffraction

\begin{abstract}
A B S T R A C T
Present study concerns with the effect of plasma nitriding on hardness of low alloy steel. Plasma nitriding had been performed at elevated temperature of $500{ }^{\circ} \mathrm{C}$ which improved the hardness to $\sim 1200 \mathrm{H}_{v}$. The case depth was found to be $\sim 80 \mu \mathrm{m}$. With the variation of time the case depth also varied. The plot of the square of the case depth $v$ s. nitriding time and the corresponding line drawn by a linear regression and extrapolation passes almost through the origin. From the plot the nitrogen diffusion co-efficient calculated to be $\sim 2.23 \times 10^{-13} \mathrm{~m}^{2} / \mathrm{s}$.

The structural and morphological studies have been made by following the X-ray diffraction (XRD) and scanning electron microscopic (SEM) and EDS analyses. XRD revealed the presence of $\alpha$-Fe, $\gamma^{\prime}$ and $\varepsilon$ phases.

(c) 2019 Elsevier Ltd. All rights reserved.

Selection and peer-review under responsibility of the scientific committee of the 1st International Conference on Manufacturing, Material Science and Engineering.
\end{abstract}

\section{Introduction}

Tool industries recently have paid attention towards the enhancement of hardness, wear and corrosion resistance properties of the tools to prolong their service life. The improvement of these properties may be done by following the surface hardening and by depositing the corrosion resistant layer. There are several physical and chemical methods which can improve these properties by depositing hard and corrosion resistant layer. Physical vapour deposition is one the popular methods to improve these surface dependent properties [1-3]. The poor adhesion of the coated layer made its application limited [4]. In this regard, nitriding has been proved to satisfy the industrial requirements for the enhancement of hardness, corrosion and wear resistance properties [5-8].

Plasma nitriding has been recognized as one of the most industrially accepted plasma mediated surface engineering methods as it is advantageous due to its environmental friendly, efficient method [9-11]. In this process the sample after polishing to mirror finish kept inside the vacuum chamber of the nitriding reactor and evacuated to low pressure. A mixture of nitrogen and hydrogen at

\footnotetext{
* Corresponding author.

E-mail address: rammohanrao.k@gmail.com (K. Ram Mohan Rao).
}

certain ratio is fed into the chamber raising the pressure to around 50-500 Pa. The substrate is biased at a -ve voltage to accelerate the positively charged ions towards it. Between the anode and cathode plasma is generated in the chamber. Nitrogen ions attract towards the substrate and adsorb on the surface and subsequently diffuse into the subsurface region. The schematic of the process is given in some other literature [12,14]. Though several reports on hardness are presented so far but less is known about wood machining tool steel. The diffusion studies have also not been known to satisfactorily.

In present work a d. c. glow discharge assisted plasma of $\mathrm{N}_{2}$ and $\mathrm{H}_{2}$ mixture at 80:20 ratio has been utilized for nitriding on low alloy steels used as the cutting tools. An attempt has been made to know about the diffusion co-efficient of nitrogen in the present study. The optimized condition of a thick and hardened layer has also been found. The process had been carried out at two different temperatures $450{ }^{\circ} \mathrm{C}$ and $500{ }^{\circ} \mathrm{C}$ at various time of exposure $3,6,8$, $10 \mathrm{~h}$ in $\mathrm{N}_{2}$ and $\mathrm{H}_{2}$ gas mixture. X-ray diffraction studies have been made for the phase evaluation. The hardness measurements were taken by utilizing Vickers's micro hardness tester. Subsequently, the case depth measurements and the diffusion co-efficient of nitrogen in the post nitrided samples were calculated.

Plasma nitriding has been recognized as one of the most industrially accepted plasma mediated surface engineering methods as 
it is advantageous due to its environmental friendly, efficient method [9-11]. In this process the sample after polishing to mirror finish kept inside the vacuum chamber of the nitriding reactor and evacuated to low pressure. A mixture of nitrogen and hydrogen at certain ratio is fed into the chamber raising the pressure to around 50-500 Pa. The substrate is biased at a -ve voltage to accelerate the positively charged ions towards it. Between the anode and cathode plasma is generated in the chamber. Nitrogen ions attract towards the substrate and adsorb on the surface and subsequently diffuse into the subsurface region. The schematic of the process is given in some other literature [12,14]. Though several reports on hardness are presented so far but less is known about wood machining tool steel. The diffusion studies have also not been known to satisfactorily.

In present work a d. c. glow discharge assisted plasma of $\mathrm{N}_{2}$ and $\mathrm{H}_{2}$ mixture at 80:20 ratio has been utilized for nitriding on low alloy steels used as the cutting tools. An attempt has been made to know about the diffusion co-efficient of nitrogen in the present study. The optimized condition of a thick and hardened layer has also been found. The process had been carried out at two different temperatures $450{ }^{\circ} \mathrm{C}$ and $500{ }^{\circ} \mathrm{C}$ at various time of exposure $3,6,8$, $10 \mathrm{~h}$ in $\mathrm{N}_{2}$ and $\mathrm{H}_{2}$ gas mixture. X-ray diffraction studies have been made for the phase evaluation.

\section{Materials and methods}

As-received sheet of the steel samples was exposed to heat treatment process. The steel sheets were austenitized and quenched in oil bath tank and then tempered at $\sim 530^{\circ} \mathrm{C}$. The steel sheets so obtained had a hardness of $\sim 657 \pm 30 \mathrm{H}_{v}$. The sheets were then cut into samples of dimensions $10 \times 10 \mathrm{~mm}^{2}$ and a thickness of $6 \mathrm{~mm}$. The chemical composition of the samples is given as: C (0.5), Mn (0.5), Cr (8.0), Mo (1.5), V (0.5), Si (1.0), Fe (88).

The metallographic sample preparations were followed from coarse to fine grits $\mathrm{SiC}$ papers and alumina suspension and to a mirror polish on the polishing wheel. Samples were then exposed to ultrasonic cleaning in acetone bath to remove the dirt and then placed in the nitriding chamber. The chamber was evacuated to an initial pressure of $0.5 \mathrm{~Pa}$ and the working pressure of $500 \mathrm{~Pa}$. Initially, the $\mathrm{Ar}^{+}$ions were sputtered on the sample surface at a pressure of $800 \mathrm{~Pa}$ and continued the sputtering until the desired temperature for the nitriding was achieved. At this stage of the process cycle the sputtering was stopped and the nitriding stage of the cycle began. The samples were kept on the sample holder biased at $-250 \mathrm{~V}$. In glow discharge assisted plasma of $\mathrm{N}_{2}$ and $\mathrm{H}_{2}$ gas mixture the nitriding process continued up to the desired length of time. Subsequent to this stage when nitriding process was complete, the cooling stage of the process cycle started whereupon the nitride samples were cooled down to room temperature.

As the temperature, time and the gas mixture influence the nitriding process, a careful study of these parameters gives the insight of the nitriding and control of the properties of the formed layer. The present work was concentrated on the influence of time and temperature by keeping the gas mixture $\mathrm{N}_{2}$ and $\mathrm{H}_{2}$ at a ratio $80: 20$. To avoid the risk of softening of the core of the sample the treatment temperature was restricted to $450{ }^{\circ} \mathrm{C}$ and $500{ }^{\circ} \mathrm{C}$. On the other hand, to understand the influence of time on the formed layer it was exposed to variable time lengths of $3,6,8$ and $10 \mathrm{~h}$. The post treated samples were subjected to Vickers's micro hardness testing (Vicker's hardness tester; Model: LECO MHT-210 micro hardness tester) at $50 \mathrm{~g}$ applied load hardness of the modified layer. To understand about the structural modifications after nitriding all the samples along with the as-received samples were exposed to detailed X-ray diffraction in Bragg Brentano mode using Co- $k_{\alpha}$ target $(0.17902 \mathrm{~nm})$.

\section{Results and discussion}

\subsection{Micro hardness profile}

The hardness depth profiles of the nitrided samples treated at different temperatures have been shown in Fig. 1. It is obvious from Fig. 1 that the increase in temperature causes an increase in hardness and also the depth of the nitrided layer. However, the increase in hardness is found to be significant at temperatures $500{ }^{\circ} \mathrm{C}$ for $8 \mathrm{~h}$ nitriding as shown in Fig. 2. At lower temperature $450{ }^{\circ} \mathrm{C}$ the depth of the hardened layer reaches to $\sim 40 \mu \mathrm{m}$ (shown in other studies), the peak hardness $1150 \pm 20 \mathrm{Hv}$ whereas at the higher temperature there is an increase in the formed layer to $\sim 80 \mu \mathrm{m}$ with peak hardness $1250 \pm 20 \mathrm{H} v$. A wider layer formation has application in the wear resisting properties. The hardness from the surface gradually decreases from a significantly high hardness to the hardness $\sim 650 \mathrm{H} v$ as observed in the as-received condition. On the other hand, at $500{ }^{\circ} \mathrm{C}$ treatment temperature the increase in treatment time from $6 \mathrm{~h}$ to $10 \mathrm{~h}$ the layer thickness increases from $\sim 40 \mu \mathrm{m}$ to $\sim 80 \mu \mathrm{m}(10 \mathrm{~h})$ where it attains the bulk hardness $\sim 657 \mathrm{H}_{v}$. Thus, the incorporation of nitrogen with increasing time to a greater depth is evidenced. If $100 \mathrm{H}_{v}$ increase of hardness over the bulk hardness $657 \mathrm{Hv}$ is considered, the layer depth ranges approximately between 110 and $120 \mu \mathrm{m}$. These results evidence the formation of large nitride layer in this type of steel after nitriding at $500{ }^{\circ} \mathrm{C}$ for $10 \mathrm{~h}$. The nitriding for a lower treatment time of $3 \mathrm{~h}$ has could not bring the improvement in the hardness significantly. This may be due to the insufficient amount of nitrogen incorporation to cause the nitride phase formation.

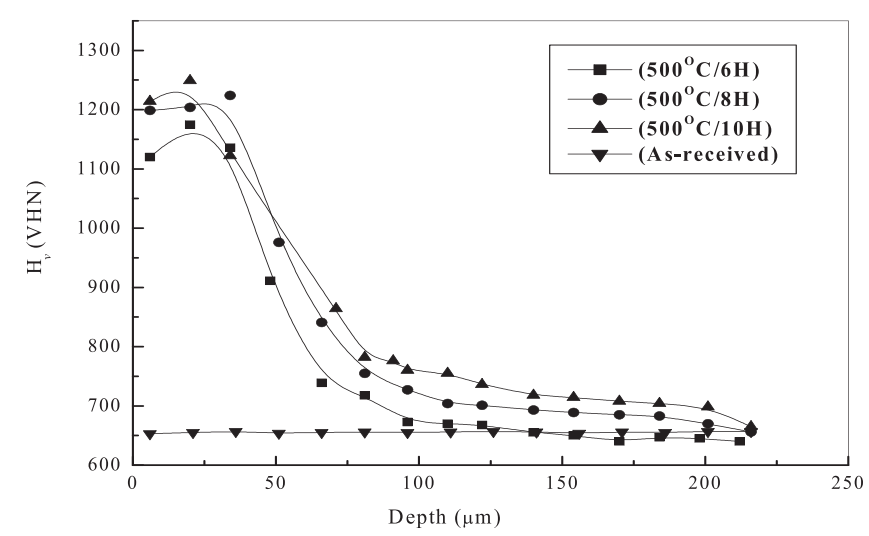

Fig. 1. Micro hardness vs. depth profile of plasma nitrided samples at $500{ }^{\circ} \mathrm{C}$ for variable treatment times.

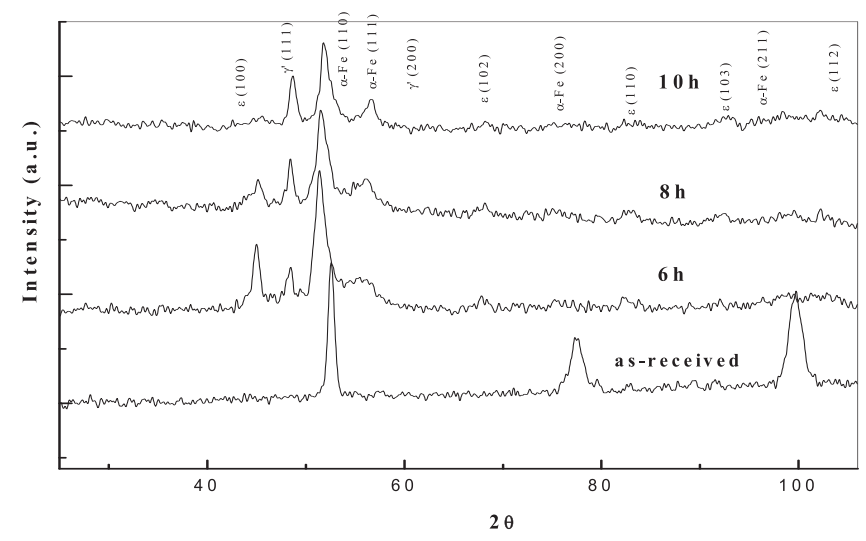

Fig. 2. Bragg-Brentano mode of X-ray diffraction of as-received and samples after plasma nitriding for variable times. 


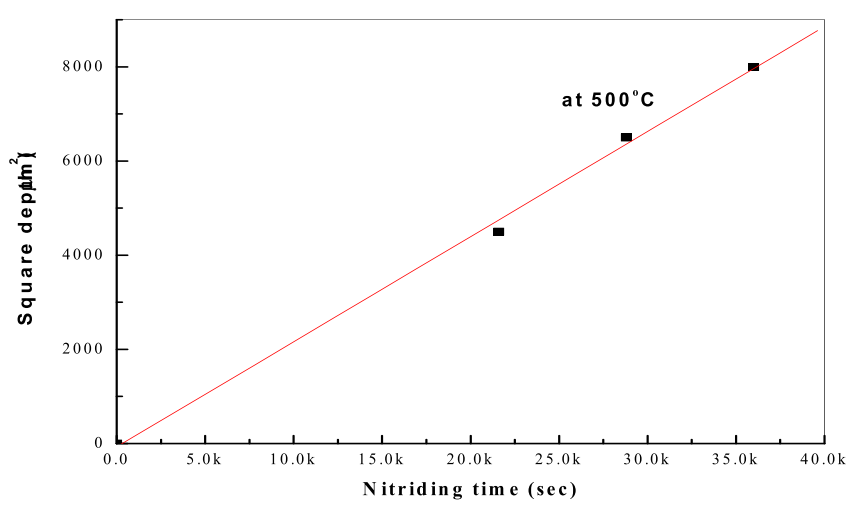

Fig. 3. Representation of the relationship of square of the case depth with variable time of nitriding process.

A diffusion gradient layer without any abrupt change as found in the case of coated layers enhances the mechanical integrity without any abrupt change in the mechanical properties.

\subsection{Phase evaluation and the modification of microstructure of the nitrided layer}

Fig. 3 reveals the diffraction patterns of the nitride samples in Bragg-Brantano geometry. The Fe $\left(\begin{array}{lll}1 & 1 & 0\end{array}\right)$ peak is found to be shifted towards the lower angle when treated at both the temperatures $450{ }^{\circ} \mathrm{C}$ and $500{ }^{\circ} \mathrm{C}$. The same can be observed with the treatment at increasing process time. The lower angle shifting may be attributed to the introduction of nitrogen in the crystal lattice and hence the generation of stress. This could be one of the reasons for the enhanced hardness and improvement in fatigue strength.

With the increase in treatment temperature the peak intensities of the $\gamma^{\prime}$ and $\varepsilon$ phases increase and also the Fe (2 111$)$ and Fe $\left(\begin{array}{lll}2 & 0 & 0\end{array}\right)$ peaks disappear. Disappearance of these peaks also occurs at $500{ }^{\circ} \mathrm{C}$ with variable treatment time. In any case, it may be attributed to the consumption of Fe causing the formation of its nitrides. When the FWHM (full width at half maximum) of the nitride peaks at low temperature is compared to the similar nitride peaks at higher temperature the latter peaks are found to be sharper. This means that with the rise of temperature more nitrogen was incorporated into the crystal lattice and also enhances its mobility to form the crystalline phases. In the entire range of nitriding process the $\varepsilon$-phases are dominating and hence accounts for the high hardness of the nitrided samples.

Thus, it can be concluded that the $\varepsilon$ and $\gamma^{\prime}$ phases are responsible for the enhanced hardness of the treated samples. Additionally, the $\varepsilon$-phases have already been recognized for its corrosion protection property [15].

\subsection{Diffusion kinetics}

Fig. 3 as shown below represents the relationship of case depth square $\left(w^{2}\right)$ with respect to variable time of nitriding. An approximate value of rate constant $(k)$ which is proportional to the diffusivity, D has been calculated from the linear regression of the given data points [16] by following the equation:

$w^{2}=k \cdot t$

Assuming that, $k$ is proportional to $\mathrm{D}$, the diffusion co-efficient (d. c.) of nitrogen in this study was calculated to be $2.23 \times 10^{-13} \mathrm{~m}^{2} / \mathrm{s}$ at $500{ }^{\circ} \mathrm{C}$ nitriding temperature. The diffusion co-efficient of nitrogen at the same temperature for glow discharge assisted plasma nitriding of $\mathrm{Fe}-19 \% \mathrm{Cr}$ (d. c. of nitrogen $=1.8 \times 10^{-13} \mathrm{~m}^{2} / \mathrm{s}$ ) is found to be comparable as compared to the d. c. of nitrogen in the present study i.e. of the same order of magnitude [17]. However, nitrogen d. c. in the conventional nitriding of plain carbon steel as obtained by Dimitrov et al. $\left(1 \times 10^{-14} \mathrm{~m}^{2} / \mathrm{s}\right)$ was found to be lower by an order of magnitude when compared to the one obtained in the present study [18]. This concludes that the plasma nitriding of steel has faster kinetics than the conventional nitriding.

\section{Conclusions}

In the present study, plasma nitriding of low alloy steel in $\mathrm{N}_{2}-\mathrm{H}_{2}$ gas mixture (80:20) proved to improve the hardness significantly which may lead to the improvement of wear resistance property. In actual service conditions for these tool steels e.g. cutting or machining tools, the wear resistance property plays a significant role to prolong their life. It has been shown in this study that the increase in treatment time increases the thickness of the nitride layer $(\sim 120 \mu \mathrm{m})$ with a significantly high hardness of $1200 \pm 30$ $\mathrm{H} v$.

The XRD analyses reveal $\varepsilon$ and $\gamma^{\prime}$-nitrides as the dominating phases in the post nitrided samples. The high hardness may be attributed to the presence of these phases and the developed micro stresses. From the earlier report it is known that the presence of $\varepsilon$ nitride is also beneficial from the corrosion resistance point of view. This would enable the cutting tools to sustain more in the corrosive environment. The plasma assisted nitriding of the steel in the present study has proved that the diffusion kinetics is faster than the conventional nitriding. The diffusion co-efficient of nitrogen in the present study is found to be $\sim 2.23 \times 10^{-13} \mathrm{~m}^{2} / \mathrm{s}$.

\section{Acknowledgements}

The support to complete the work and given the permission to present by GITAM Deemed to University is thankfully acknowledged. Support received from ENSAM, France is gratefully acknowledged.

\section{References}

[1] J.R. Roth, Industrial Plasma Engineering, Vol. 1: Principles, IOP Publishing Ltd., Bristol, 1995.

[2] M. Ohring, The Material Science of Thin Films, Academic Press, San Diego, 1992.

[3] T. Michler, Surf. Coat. Technol. 202 (2008) 1688.

[4] I. Wang, Y. Li, X. Wu, Appl. Surf. Sci. 254 (20) (2000) 6595.

[5] T. Czerviec, H. Michel, E. Bergman, Surf. Coat. Technol. 108 (1998) 182

[6] M.K. Lie, Z.I. Zhang, T.C. Ma, Surf. Coat. Technol. 131 (2000) 317.

[7] Thierry Czerviec, Huan He, Gregory Marcos, Tony Thiriet, Sylvain Weber, Henri Michel, Plasma Process. Polym. 6 (2009) 401.

[8] I. Marot, I. Pichon, M. Drouet, A. Straboni, Mater. Lett. 44 (2000) 35

[9] V.A. Alves, C.M.A. Brett, A. Cavaleiro, Surf. Coat. Technol. 161 (2002) 257.

[10] M.A.M. Ibrahim, S.F. Korablov, M. Yoshimura, Corr. Sc. 44 (2002) 815.

[11] A. Sokolowska, J. Rudnicki, E. Wnukowski, P. Beer, T. Wierzchori, K.J. Kurzydlowski, J. Achiev. Mater. Manuf. Eng. 37 (2009) 690.

[12] A.S. Loir, D. Pech, P. Steyer, Y. Gachon, C. Héau, J.C. Sanchz-Lopez, Plasma Process. Polym. 4 (2007) 173.

[14] D. Liedtke, U. Huchel, et al., Wärmebehandlung von Eisenwerkstoffen, Nitrieren und Nitrocarburieren, 3rd ed., Epertverlag, 2005.

[15] P. Steyer, J.-P. Millet, J.-P. Peyre, P. Jacquet, D. Hertz, Surf. Eng. 19 (2003) 173.

[16] I. Manna, J. Datta Mazumdar, J. Mater. Sci. Lett. 12 (1993) 920.

[17] J. Takada, Y. Ohizumi, H. Miyamura, H. Kuwahara, S. Kikuchi, I. Tamura, J. Mater. Sci. 21 (1986) 2493.

[18] V.I. Dimitrov, J.D. H'aen, G. Knuyt, C. Quacyhaegens, L.M. Stals, Surf. Coat. Technol. 179 (1980) 327.

\section{Further reading}

[13] L. Chekour, C. Nouveau, A. Chala, M.A. Djouadi, Surf. Coat. Technol. 200 (2005) 512, (1-4 SPEC, 155). 